\title{
Baby Bust: Falling Fertility in US Counties Is Associated with COVID-19 Prevalence and Mobility Reductions
}

Philip N. Cohen

University of Maryland

Revised: July 4, 2021

\begin{abstract}
The United States experienced a 3.8 percent decline in births for 2020 compared with 2019, but the rate of decline was much faster at the end of the year (8 percent in December), suggesting dramatic early effects of the COVID-19 pandemic, which began affecting social life in late March 2020. Using birth data from Florida and Ohio counties through February 2021, this analysis examines whether and how much falling birth rates were associated with local pandemic conditions, specifically infection rates and reductions in geographic mobility. Results show that the vast majority of counties experienced declining births, suggestive of a general influence of the pandemic, but also that declines were steeper in places with greater prevalence of COVID-19 infections and more extensive reductions in mobility. The latter result is consistent with more direct influences of the pandemic on family planning or sexual behavior. The idea that social isolation would cause an increase in subsequent births receives no support.
\end{abstract}




\section{Baby Bust: Falling Fertility in US Counties Is Associated with COVID-19 Prevalence and Mobility Reductions}

\section{Introduction}

The COVID-19 pandemic has affected many aspects of social life, radiating outward from direct infections to family members and caregivers, to schools and workplaces, local and national economies and the global economy. In the United States, excess mortality for the year 2020 was about 450,000, or 17 percent higher than expected, according to the Centers for Disease Control and Prevention (Centers for Disease Control 2021). As a result of the pandemic, the unemployment rate spiked from less than 4 percent to more than 14 percent in April, and by the end of 2020 was still higher than 6 percent (Bureau of Labor Statistics 2021). The effects were disparate. In addition to substantial geographic variation, rates of infection, hospitalization, and mortality from the disease were much higher among American Indians, Hispanics, and African Americans than among nonHispanic Whites (CDC 2021). In the Census Pulse survey, 47 percent of adults reported that they or a household member lost income or a job between March 2020 and the end of the year, and that experience was much more common among low-income households (US Census Bureau 2021).

From mid-March 2020, social life was restricted in many ways, with implications for public health, including pregnancy and childbirth. Despite initial speculation that excess time at home might lead to an increase in sexual activity and births (Puente 2020), historical experience suggested a disaster of this scale would lead to a substantial decline in fertility, especially in wealthy societies (Aassve et al. 2020). The 1918 influenza pandemic led to a sharp reduction in U.S. births, with recovery on a period basis in the years that followed (Wagner et al. 2020). More recently, epidemics have generally been associated with declines in fertility at least in the short term, provided access to contraception is not severely limited (Ullah et al. 2020). With regard to economic changes, recent cohorts of U.S. women exposed to increases in unemployment have experienced lifetime reductions in births (Currie and Schwandt 2014).

As the COVID-19 pandemic swept around the world in 2020, survey evidence revealed changing fertility intentions, with a substantial proportion of people indicating they would postpone or forego births because of the pandemic in both Europe (Luppi, Arpino, and Rosina 2020) and the United States (Lindberg et al. 2020), as desire to prevent pregnancy ran up against problems accessing contraception for the poorest women (Lin et al. 2021). An analysis of Google search behavior from mid-2020 foretold a decline in U.S. birth rates of about 15 percent from November 2020 through 
February 2021 (Wilde, Chen, and Lohmann 2020). In the event, U.S. births fell 3.8 percent for the year 2020, but were off 6 percent in November and 8 percent in December, as births from pregnancies begun in February and March 2020 were tallied (National Center for Health Statistics 2021). This represents an acceleration of the decline over the previous three years (Figure 1).

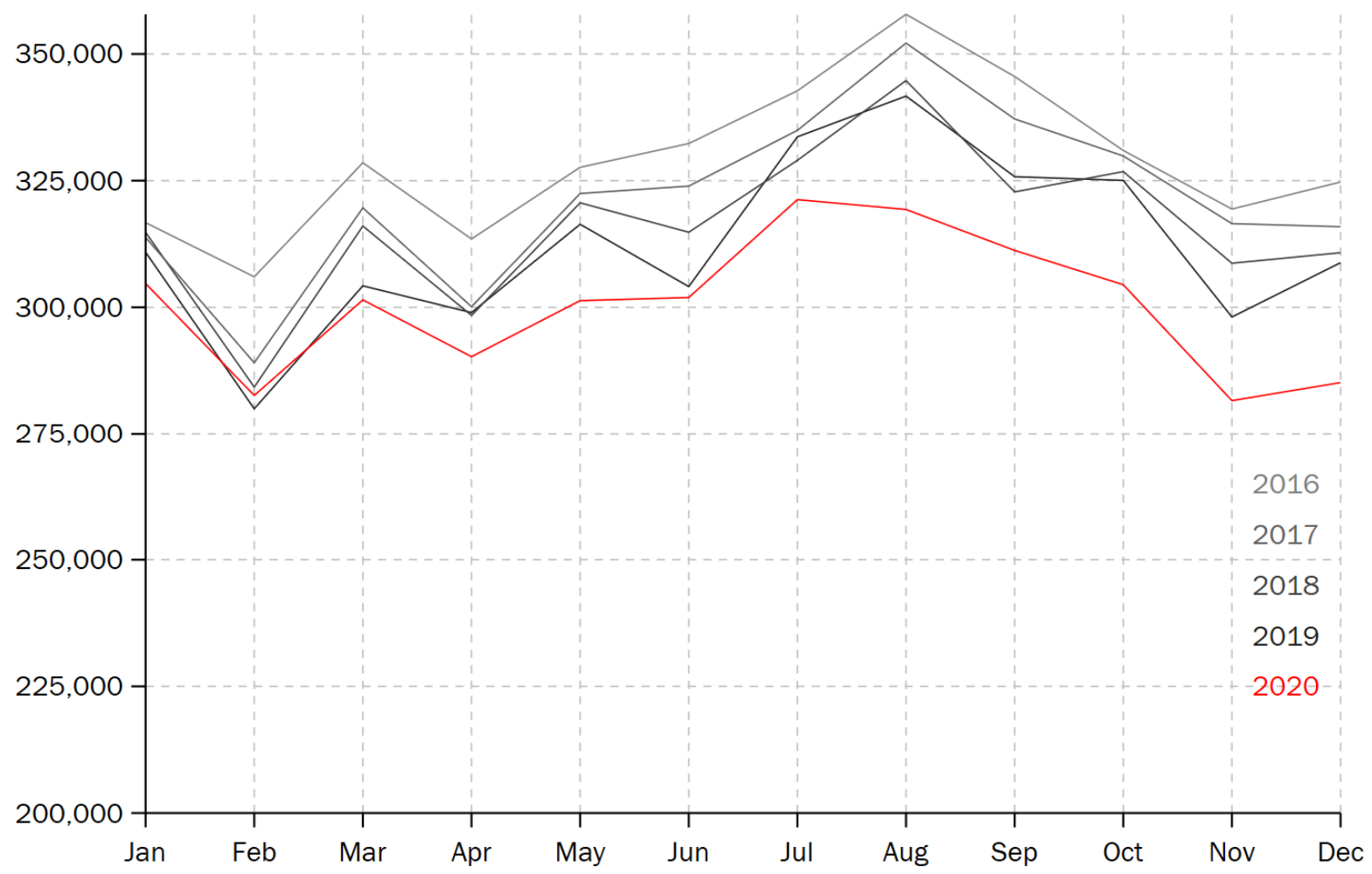

Figure 1. US births per month, 2016-2020. From the National Center for Health Statistics (2021).

At this writing, we do not yet have the data adequate to discern the mechanisms behind the decline in U.S. fertility following the COVID-19 outbreak. Among nine states with monthly reports through at least December 2020, all appear close to the national average of a drop between 5 percent and 10 percent for the last two months of the year, which the exception of Hawaii, which registered a steeper drop in the preliminary data (Figure 2). Note also that among those with the latest data, first month or two of 2021 showed the greatest relative declines in most of these, with marked rebounds already registered in California, Florida, and Ohio. This suggests a systemic effect. 

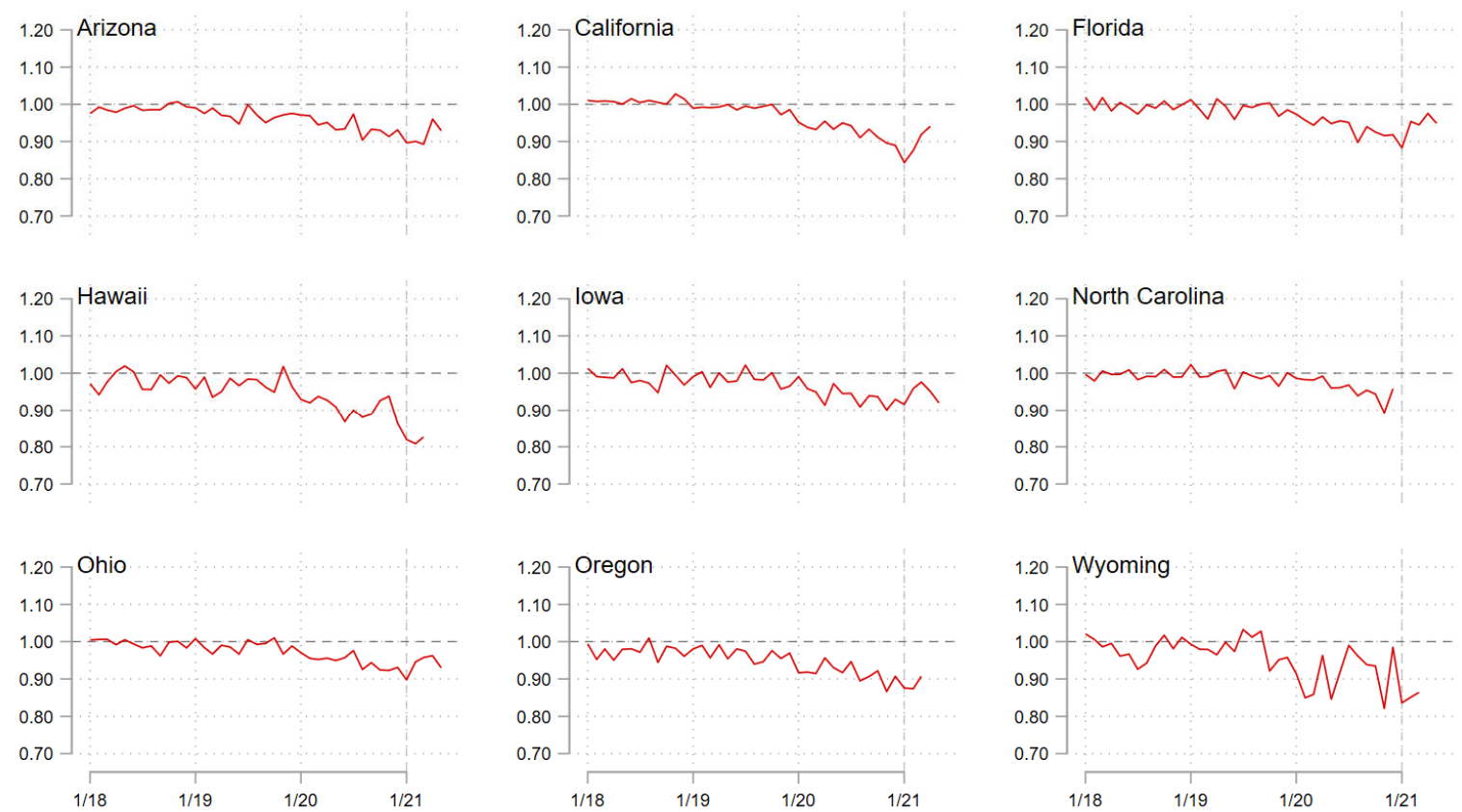

Figure 2. Births per month in nine states, 2018-2021, expressed as a ratio of births to the 20162020 average for each month. From state vital statistics offices (see data and methods).

Although the data are not adequate for extensive hypothesis testing, in what follows I examine three possibilities, and subject them to a simple test of plausibility using data from two states with good county-level data that runs through February 2021: Florida and Ohio. First, COVID-19 may have direct effects on birth rates through disease infection (of self or family members) and its consequences, or from the social isolation imposed formally and informally. For example, people who are themselves sick, whose relatives are sick, or who are shut in at home for extended periods may be less sexually active (or fecund), and more motivated to prevent pregnancy. The virus may also have medical effects on fecundity or birth outcomes (Karimi et al. 2021; Seymen 2021), including preterm birth (Joseph, Rasmussen, and Jamieson 2021). This would be consistent with strong correlations between local infection rates or social mobility and birth rates nine to ten months later.

Second, the pandemic may have a more diffuse impact, with insecurity about health problems and economic fears leading to broad changes in fertility intentions and changes in social interaction that are not strongly correlated with observed local impacts. This would be consistent with weak correlations at the local level. Third, time spent in isolation might lead to more sexual frequency among coresidential couples, leading to increased birth rates nine to ten months later. This would be consistent with a positive correlation between local shutdowns and subsequent birthrates. 
An ecological analysis with limited data, such as that conducted here, cannot fully assess these mechanisms for pandemic influences on birth rates. In particular, the possibility of disparate impacts by age, economic status, race/ethnicity, and other factors cannot be examined here. Instead, this analysis offers a first pass at assessing the plausibility of these (or other) mechanisms, helping to motivate further research as suitable data become available.

\section{Data and methods}

The outcome measure for this study is the number of births registered per county by state authorities. For each county month, I calculate the ratio of births to the average for that county and calendar month for the years 2016-2019 (hereafter, "birth change"). Scores below 1 indicate a relative decline in the number of births for each county relative to the reference period. After showing the trends by month for nine states (Figure 2), I create an average birth change for the months of January and February 2021 for counties in Florida and Ohio. Combining two months is intended to reduce noise in the measure from the arbitrary division into months. These two months are the latest available, and reflect births conceived in April and May. The Trump administration issued national guidelines for social restriction on March 16 (Rogers and Cochrane 2020). This outcome measure does not take into account changes to the population at risk from aging, migration, or mortality. The fertility sources and data are available from (Cohen 2020a). State reports of births at the county level are provisional and subject to revision. Checking the reporting for these two states on a regular basis (>1 / week) over several months reveals that by the end of the following month the numbers are quite stable, with only very small additions if any; I extracted these counts on March 16, 2021. To measure the impact of the virus, I use the total number of confirmed infections per 1,000 residents by May 31, 2020, as reported by state or county authorities and aggregated by the New York Times, with 2018 population denominators from the U.S. Census Bureau (hereafter, "infection rate"). The pandemic and population data are available from (Cohen 2020b). Rather than use a measure of behavior restriction policies such as mask mandates, which are of uncertain efficacy (Guy 2021), I use a Google Community Mobility Reports (Google 2021), which report the level movement within counties expressed as a percentage of movement in the baseline period (January 3 to February 6, 2020). I average movement across five types of location: retail and recreation, groceries and pharmacies, transit stations, workplaces, and residences. Lower negative scores indicate greater reductions in movement. To create a single indicator for each county, I use the lowest point in the seven-day average of the combined measure for each county before May 31 , 2020 (hereafter, “mobility change”). 
Florida as 68 counties, 43 of which had sufficient data for analysis; Ohio has 90 counties, 81 of which had sufficient data. I also excluded two counties in Ohio (Marion and Pickaway) whose early COVID-19 infections were dominated by large outbreaks in prisons. The final sample represents 98 percent of the population of Ohio and 95 percent of the population of Florida. I truncated a small number of outliers in low-population counties at 0.6 on the low end of birth change $(n=4)$ and 1.4 at the high end $(n=7)$. In the analysis, I present linear fits between infection rates, mobility, and fertility change, weighted by county population. Then I estimate an OLS regression on birth rates with both infection rates and mobility, also weighted by population, and a control for state (Florida $=1)$. Stata code to retrieve the data and produce the tables and figures in this paper is available at: https://osf.io/nspre/.

\section{Results}

Data for the 12 largest counties by population are presented in Table 1. Birth changes for JanuaryFebruary 2021 range from .80 in Miami-Dade, Florida to 1.07 in Polk, Florida, with an average of .92. The trends in birth change for these 12 counties are shown in Figure 3, with all 12 showing either declines or no trend over the course of 2020 into 2021. Infection rates for these counties are shown in Figure 4, ranging from 6.5 per 1,000 at the end of May, 2020 in Miami-Dade, to 1.3 in Pinellas, Florida. Finally, the mobility change trends are shown in Figure 5, with troughs ranging from -41.6 in Orange, Florida, to -23.8 in Polk, Florida. 
Table 1. Twelve largest counties by population in Florida and Ohio

\begin{tabular}{|c|c|c|c|c|c|}
\hline & & Population & Birth change & $\begin{array}{l}\text { Infection } \\
\text { rate }\end{array}$ & $\begin{array}{l}\text { Mobility } \\
\text { change }\end{array}$ \\
\hline \multirow[t]{9}{*}{ Florida } & Miami-Dade & $2,761,581$ & .804 & 6.5 & -36.4 \\
\hline & Broward & $1,951,260$ & .841 & 3.7 & -35.1 \\
\hline & Palm Beach & $1,485,941$ & .924 & 4.0 & -33.1 \\
\hline & Hillsborough & $1,436,888$ & .899 & 1.5 & -33.8 \\
\hline & Orange & $1,380,645$ & .973 & 1.4 & -41.6 \\
\hline & Pinellas & 975,280 & .882 & 1.3 & -30.0 \\
\hline & Duval & 950,181 & .961 & 1.7 & -26.3 \\
\hline & Lee & 754,610 & .984 & 2.5 & -36.9 \\
\hline & Polk & 708,009 & 1.068 & 1.5 & -23.8 \\
\hline \multirow[t]{3}{*}{ Ohio } & Franklin & $1,310,300$ & .884 & 4.5 & -29.5 \\
\hline & Cuyahoga & $1,243,857$ & .902 & 3.6 & -29.3 \\
\hline & Hamilton & 816,684 & .891 & 3.3 & -25.2 \\
\hline
\end{tabular}

Ratio of births to 2016-2019 average for each month
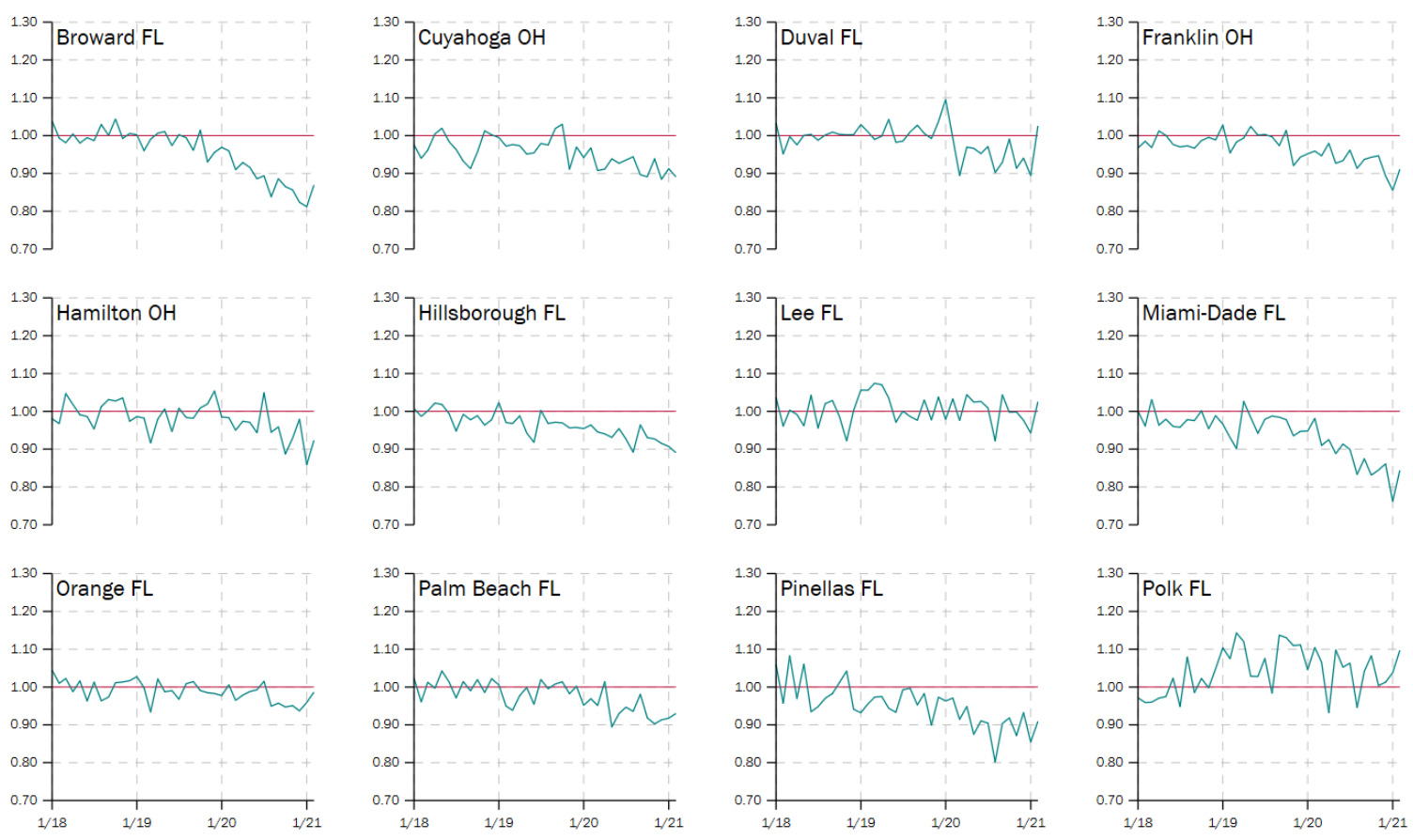

Figure 3. Births by month, 2018-2021: Most populous counties. 
Cases per 1,000 population
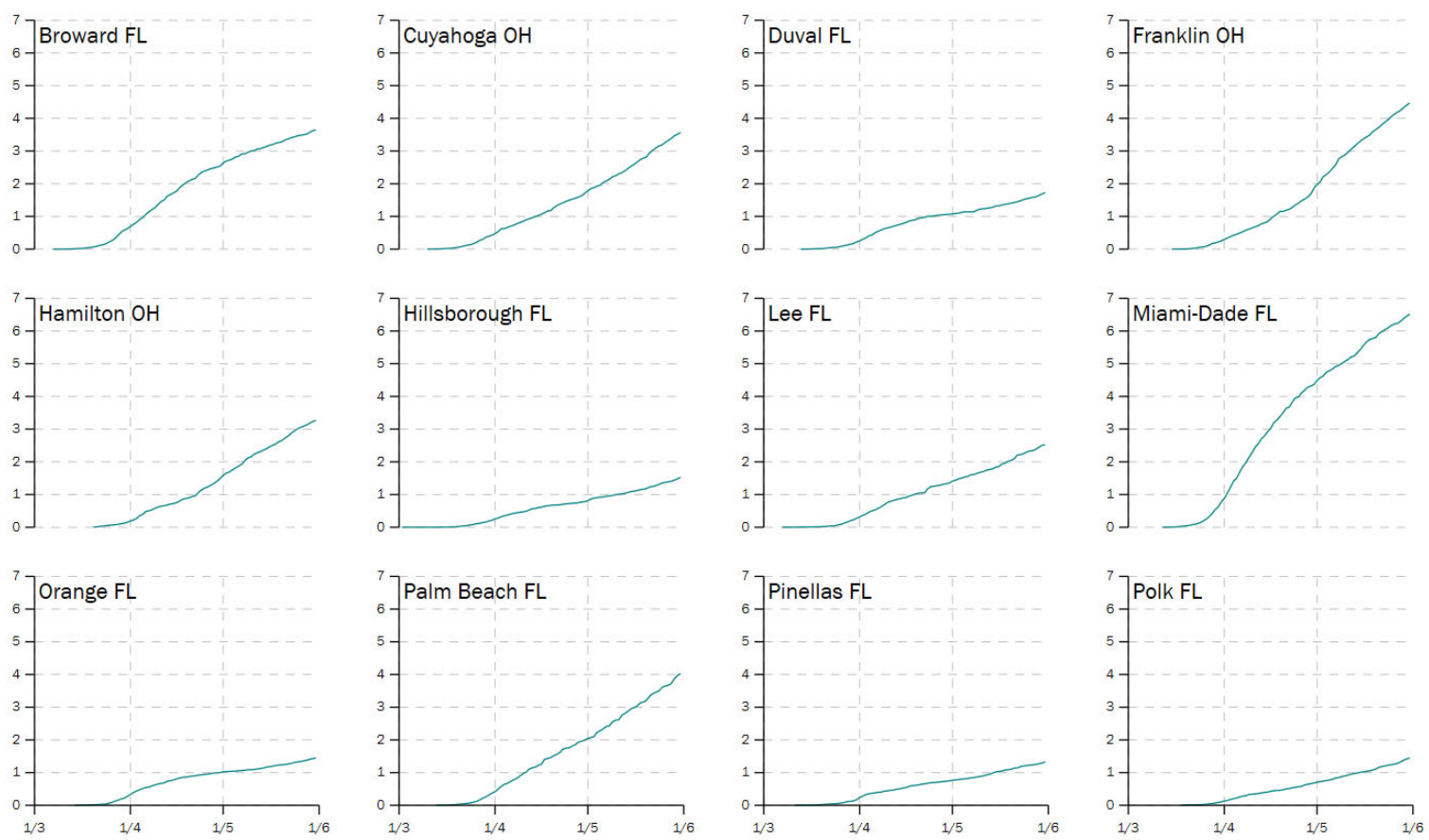

Figure 4. COVID-19 confirmed cases per capita through May 31, 2021: Most populous counties.

Mobility for shopping, transit stations, workplaces, and residences, as percent change from Jan 3-Feb 6
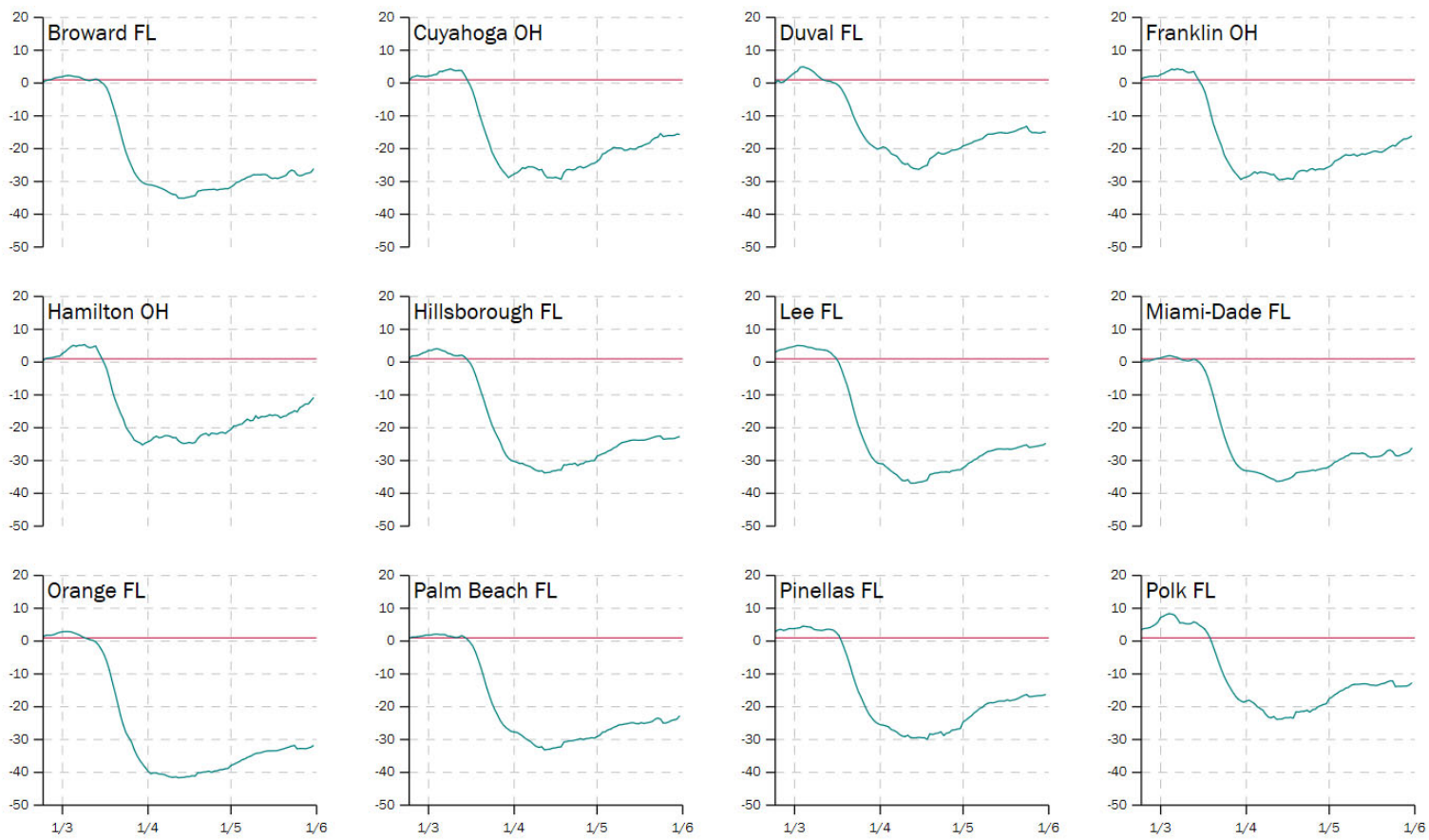

Figure 5. Local mobility levels through May 31, 2021: Most populous counties. 
The correlations between birth change and $(A)$ infection rate and $(B)$ mobility reduction are shown in Figure 6 . The birth change correlation with infection rate is $-.34(p<.001)$, and with mobility reduction is .20 ( $p$ <.05). The figure also shows that of the 124 counties, $102(82 \%)$ have birth change below 1 , indicating fewer births than the county average from 2016-2019. These counties include 27.8 million residents, or 87 percent of the total sample.
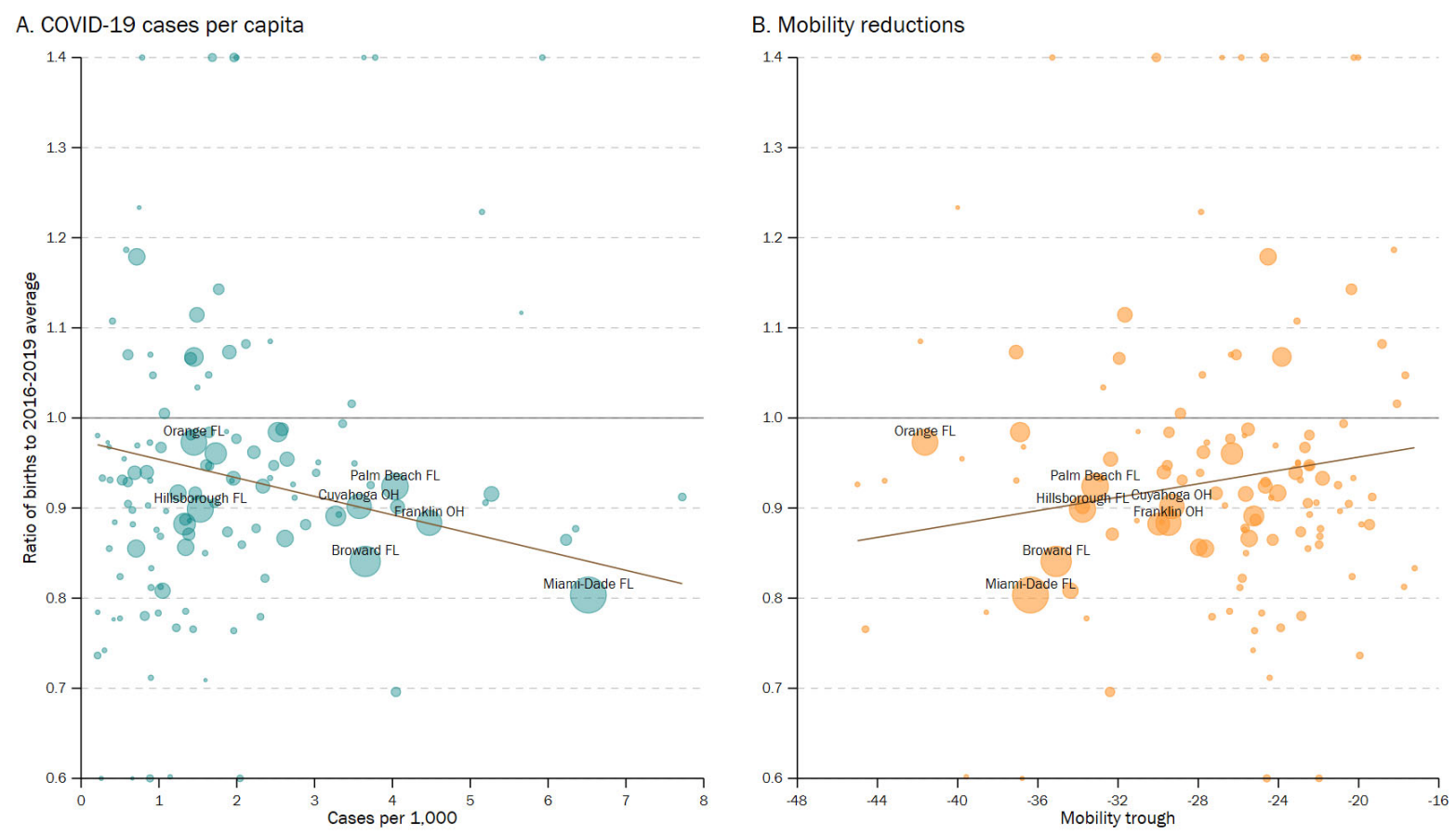

Figure 6. Ratio of births to 2016-2019 average and (A) COVID-19 cases per capita and (B) mobility reductions. With linear fits weighted by population. Points are scaled to population size. Counties with population $>1$ million are labeled.

The result of the OLS regression are presented in Table 2, which confirms the negative effect of infection rate and the positive effect of mobility change, such that higher levels of infection, and greater reductions in mobility through May 31, 2021, are associated with greater declines in fertility in January and February 2021. 
Table 2. OLS regression for birth change on infection rate and mobility change

\begin{tabular}{lrrcr}
\hline & Coefficient & SE & Confidence interval & $p$ \\
\cline { 2 - 5 } Infection rate & .017 & .005 & $-.028--.006$ & .003 \\
Mobility change & .004 & .002 & $.000-.008$ & .037 \\
State (Florida=1) & .044 & .023 & $.000-.089$ & .051 \\
Constant & 1.062 & .050 & $.962-1.162$ & \\
\hline R-squared & .155 & & & \\
$N=124$ & & & & \\
\hline
\end{tabular}

\section{Discussion}

The end of 2020 and beginning of 2021 saw dramatic decreases in births in the United States. The 3.8 percent drop reported for the year 2020 by the CDC is the largest one-year fertility decline on a percentage basis since the end of the Baby Boom in 1965. Birth rates were already falling in the years leading up to 2020 (Hartnett and Gemmill 2020), but the increasing pace of decline at the end of the year strongly implies an effect of the global COVID-19 pandemic, which struck in early 2020.

These results are consistent with the suggestion that direct effects of the pandemic, beginning for most people in late March, in terms of infections in people's families or personal networks, and limitations on social mobility from formal or informal restrictions, led to a reduction in pregnancies and subsequent births. We cannot know from this analysis to what extent such reductions reflected efforts to prevent pregnancy or birth, versus (or in addition to) reductions in unplanned pregnancies through reduced social contact or sexual frequency.

The correlation between local conditions and subsequent birth rates points toward possible direct influences. However, the decline in births was national in 2020 , and in the states under study here 87 percent of people live in counties with birth rates that dropped in January and February, relative to previous years. Thus a pattern of more general influence, through wider economic or health effects and uncertainties, for example, would also be consistent with this analysis.

Finally, these results provide no support for the suggestion that excess time during formal or informal shutdowns and mobility restrictions led to higher birth rates as a result of increased sexual frequency. Of course, future research may reveal that some births may resulted from such influences, but at this point they are apparently not enough to register as positive effects in the aggregate data used here.

The results reported at the national level (National Center for Health Statistics 2021), in addition to the state data presented here, do not yet show evidence of a slowing in fertility declines associated 
with the pandemic. How far birth rates will far, and for how long, remains to be seen. In addition, the diffusion of falling birth rates across groups in the population, especially by age, economic status, and race/ethnicity, are vitally important, and must be determined by future research.

\section{References}

Aassve, A., N. Cavalli, L. Mencarini, S. Plach, and M. Livi Bacci. 2020. "The COVID-19 Pandemic and Human Fertility." Science 369(6502):370-71. doi: 10.1126/science.abc9520.

Bureau of Labor Statistics. 2021. "Employment Situation Summary." Retrieved March 15, 2021 (https://www.bls.gov/news.release/empsit.nrO.htm).

CDC. 2021. "Cases, Data, and Surveillance." Centers for Disease Control and Prevention. Retrieved March 16, 2021 (https://www.cdc.gov/coronavirus/2019-ncov/covid-data/investigationsdiscovery/hospitalization-death-by-race-ethnicity.html).

Centers for Disease Control. 2021. "Excess Deaths Associated with COVID-19." Retrieved March 15, 2021 (https://data.cdc.gov/NCHS/Excess-Deaths-Associated-with-COVID-19/xkkf-xrst).

Cohen, Philip N. 2020a. “Baby Bust.” doi: 10.17605/OSF.IO/PVZ3G.

Cohen, Philip N. 2020b. "Coronavirus.” doi: 10.17605/OSF.IO/WD2N6.

Currie, Janet, and Hannes Schwandt. 2014. "Short- and Long-Term Effects of Unemployment on Fertility." Proceedings of the National Academy of Sciences 111(41):14734-39. doi: 10.1073/pnas.1408975111.

Google. 2021. "COVID-19 Community Mobility Report." COVID-19 Community Mobility Report. Retrieved March 17, 2021 (https://www.google.com/covid19/mobility?hl=en).

Guy, Gery P. 2021. “Association of State-Issued Mask Mandates and Allowing On-Premises Restaurant Dining with County-Level COVID-19 Case and Death Growth Rates - United States, March 1-December 31, 2020." MMWR. Morbidity and Mortality Weekly Report 70. doi: $10.15585 / \mathrm{mmwr} . \mathrm{mm} 7010 \mathrm{e}$.

Hartnett, Caroline Sten, and Alison Gemmill. 2020. "Recent Trends in U.S. Childbearing Intentions." Demography 57(6):2035-45. doi: 10.1007/s13524-020-00929-w.

Joseph, Naima T., Sonja A. Rasmussen, and Denise J. Jamieson. 2021. "The Effects of COVID-19 on Pregnancy and Implications for Reproductive Medicine." Fertility and Sterility. doi: 10.1016/j.fertnstert.2020.12.032.

Karimi, Leila, Somayeh Makvandi, Amir Vahedian-Azimi, Thozhukat Sathyapalan, and Amirhossein Sahebkar. 2021. "Effect of COVID-19 on Mortality of Pregnant and Postpartum Women: A Systematic Review and Meta-Analysis." Journal of Pregnancy 2021:e8870129. doi: $10.1155 / 2021 / 8870129$. 
Lin, Tracy Kuo, Rachel Law, Jessica Beaman, and Diana Greene Foster. 2021. "The Impact of the COVID-19 Pandemic on Economic Security and Pregnancy Intentions among People at Risk of Pregnancy." Contraception. doi: 10.1016/j.contraception.2021.02.001.

Lindberg, Laura D., Alicia VandeVusse, Jennifer Mueller, and Marielle Kirstein. 2020. Early Impacts of the COVID-19 Pandemic: Findings from the 2020 Guttmacher Survey of Reproductive Health Experiences. Guttmacher Institute.

Luppi, Francesca, Bruno Arpino, and Alessandro Rosina. 2020. "The Impact of COVID-19 on Fertility Plans in Italy, Germany, France, Spain, and the United Kingdom." Demographic Research 43(47):1399-1412. doi: 10.4054/DemRes.2020.43.47.

National Center for Health Statistics. 2021. "Provisional Estimates for Selected Maternal and Infant Outcomes by Month, 2018-2020." Retrieved March 15, 2021 (https://www.cdc.gov/nchs/covid19/technical-notes-outcomes.htm).

Puente, Maria. 2020. "Will Coronavirus Cause a Baby Boom, or Is That Just a Myth? Prepare for Jokes, If Not Babies!” USA Today, April 2.

Rogers, Katie, and Emily Cochrane. 2020. "Trump Urges Limits Amid Pandemic, but Stops Short of National Mandates." The New York Times, March 16.

Seymen, Cemile Merve. 2021. "The Other Side of COVID-19 Pandemic: Effects on Male Fertility." Journal of Medical Virology 93(3):1396-1402. doi: https://doi.org/10.1002/jmv.26667.

Ullah, Md. Asad, Abu Tayab Moin, Yusha Araf, Atiqur Rahman Bhuiyan, Mark D. Griffiths, and David Gozal. 2020. "Potential Effects of the COVID-19 Pandemic on Future Birth Rate." Frontiers in Public Health 8. doi: 10.3389/fpubh.2020.578438.

US Census Bureau. 2021. "Week 22 Household Pulse Survey: January 6 - January 18." Census.Gov. Retrieved March 16, 2021 (https://www.census.gov/data/tables/2021/demo/hhp/hhp22.html).

Wagner, Sander, Felix C. Tropf, Nicolo Cavalli, and Melinda C. Mills. 2020. "Pandemics, Public Health Interventions and Fertility: Evidence from the 1918 Influenza."

Wilde, Joshua, Wei Chen, and Sophie Lohmann. 2020. COVID-19 and the Future of US Fertility: What Can We Learn from Google? SocArXiv. 